\title{
Informal Education of Adolescents
}

\author{
Elena Chernikova ${ }^{1, *}$, Nadezhda Sivrikova ${ }^{1}$, and Tatyana Ptashko ${ }^{1}$ \\ ${ }^{1}$ South Ural State Humanitarian Pedagogical University, 69 Lenin ave., Chelyabinsk, Russia
}

\begin{abstract}
The present article reveals the concept and the significance of the informal component of educational environment designed for modern adolescents. The authors provide the analysis of Russian and foreign research in the field of adolescents education through their mediaconsumption; the analysis of gender disparities of self-actualization in the Internet environment. The study presents aspects of positive and negative impact of the Internet on the personal and intellectual development of adolescents, as well as on their socialization and psychological well-being (Internet-addiction). The empirical research identified trends in adolescents' attitude towards Internet, books and their role in educational process. The results show that adolescents mostly apply to the Internet, books and TV as a source of informal education. The Internet plays a considerable role in the life of adolescents. More than a half of those who took part in the survey spend all their free time surfing the Internet. On the Internet, the adolescents mostly watch foreign movies, read books which have positive feedbacks on forums; they do it both to broaden their horizons and enlarge life experience in general. Through the Internet, adolescents - both girls and boys - make more friends, they more prominently articulate their opinion, and become more tolerant. Only one in ten mentioned the negative impact of the Internet on his/her psychological state.
\end{abstract}

\section{Introduction}

Today's school education is considered as an important condition for the development of the Russian society as a whole. And its role in preparing personal and professional selfidentification of the younger generation is specifically emphasized. However it should be noted that the adolescents' attitude towards studies is generally mixed. The results of the study indicated the increase in the number of schoolchildren showing negative attitude to education. The number of NEET young people is growing and includes adolescents aged from 15 unwilling to receive education or to be involved in any initiatives [1].

With that adolescents feel greater importance of successful professional activity. However the value of raising their level of education and broadening their horizons become less significant [2]. Positive attitude to education is discussed in works by I. I. Vartanova. Her research shows that adolescents refer to in-depth knowledge and successful career as important for them [3]. This has been also proofed by foreign authors who stressed that

\footnotetext{
* Corresponding author: bobronv@ cspu.ru
} 
both performance and academic well-being play a certain role in training adolescent students and on finishing school [4].

The attitude of adolescents towards education depends on a variety of factors, though it is only independent of the very interaction between the teacher and the student.

Modern education may be viewed in a broad context. Thus, L. I. Guslyakova believes it can be represented in the form of formal education that completes with the award of a corresponding certificate; non-formal education involving the individual into students' selfgovernment bodies, and unions and informal education providing individual cognitive work that accompanies people in their everyday life [5].

The informal component means that the adolescents get new knowledge from different information cognitive sources. These are most popular among young people and include the Internet, books, and TV programs. In this relation, it is highly important to find out the role of the aforementioned sources in the life of a modern adolescent and to assess the impact they have on the adolescents' further personal and intellectual development.

The sufficient number of studies deals with the role of the Internet in the life of a modern person. The researchers agree that today's youth is increasingly becoming involved in media and transfer traditional communicative practices in the virtual world $[6,7]$. Russian [8,9] and foreign scientists $[10,11,15]$ mark greater attachment of adolescents to the Internet and its high impact on their lives and ways to receive additional information. The Western authors pay higher attention to the analysis of psychological aspects of the use of social networks. This is due to the fact that in the Western countries social networks have become extremely popular, with such platforms as Facebook, Instagram, Twitter, Snapchat, Tumblr and others among them. According to the survey conducted by the Pew Research Center in $2015,89 \%$ of adolescents reported their use of at least one social network, $71 \%$ of adolescents said they use more than one social network [12]. Such data cause great scientific interest to investigating young people's behavior in social networks. In particular, the studies showed that the use of Facebook have negative impact on the adolescents' sense of self [13], as well as distorts the perception of their peers' sexual behavior and affects their intentions towards such behavior [14].

The researchers and practitioners feel the greatest concern about the Internet-addiction. Among the factors developing the Interned-addiction in adolescents there is the participation in forums and the low level of self-acceptance. Foreign scientists such as. Scott, Simecka and others showed that addiction to technologies reduces the level of social skills, self-motivation, and intellect [17]. Malaysian scientists have found out that the use of the Facebook social network may be related to the obsessive compulsive disorder [18]. In China such matters as the impact of the Internet on the moral ground of the youth [19].

On the other hand we have also seen the positive impact of the Internet-based communication on the vital activity of the adolescents. Thus, it has been found that the number of friends on Facebook has a positive effect on self-control and initiation of autonomous relationships [20].

The scientists have proofed that the Internet access and the use of definite applications at home, as well as the use of Information and Communications Technologies in class greatly and positively affects the development of cognitive skills [21]. Students also express positive attitude towards the use of social media in education $[7,22,23]$.

Gender disparities in the use of the Internet are becoming a new independent field of research. The analysis of the Internet audience shows that the gender disparities correlate with the experience and the skill of surfing the Internet as well as the cultural factor, particularly of the country of residence [23].

The scientific works give us contradictory information on different media attractiveness to different genders. It has been noted that males mostly show higher attachment to the Internet than females [24]. 
We believe that the present question requires further investigation as the existing data do not allow drawing a clear conclusion on gender disparities in choosing these or those media.

The study of the gender identity in Facebook social network profiles showed that in the age of 12-17 females are more inclined to follow gender stereotypes, than males [25]. The pictures used by males accentuate their status, while those of females show their family life and emotions [26]. Besides, the use of social networks by adolescents of both genders is based on different motives. The girls are engaged over social media with those who they like and with their mates, while boys are more likely to use social media in order to compensate their real life failures and to search for recognition [27].

We differentiate male and female users of the Internet. For females it is mostly the means of communication and keeping social connections. While males' structure of activity is broader. Thus, according to the survey data females are more likely to send and receive messages, while males are engaged in navigating websites and downloading information [23]. In computer online games males are more oriented towards achievements and more aggressive, while females enjoy the gameplay process itself [28].

There is a certain asymmetry in the interest expressed by female Internet users towards humanitarian knowledge and informal communication. More females than males are interested in receiving information on education, culture and arts, traveling and tourism, family and children, health and dieting, leisure and hobbies. They are less interested in information about software and computer science, Internet latest news, sports, different goods and prices, policy, and information "for adults only" than males [29]. Gender disparities of self-actualization in the Internet were discovered by N.S. Kozlova and E. N. Komarova. Their research showed that the male users are more active on the Internet. Along with the use of the Internet as a means of solving certain tasks and entertaining, males self-actualize in creative, personal and sexual spheres. Females are mainly involved in communication and self-presentation, and sometimes the real self-actualization is replaced by self-expression [30]. Females show higher motivation to communication (especially informal), as males manifest more cognitive interest. Answering the question about the most significant disadvantages if the Internet more females than males feel concern about moral and mental issues, while males are dissatisfied with the technical imperfection [27].

A greater number of schoolchildren use the Internet to obtain information of the occupations (27.7\%) [33], which may also prove the increasing role of informal education in people's lives.

Thus, there are extensive data on the fact that media-consumption is related to the learning process and the personal development of adolescents. The study revealed gender disparities in media-consumption in young people. These data however are not sufficient to characterize informal education.

\section{Design/methodology/approach}

The present research is focused on revealing modern trends in the attitude of adolescents towards the Internet and books and their role in educational process.

The empirical research is based on the data collected in 2018 in municipal generaleducation schools of Chelyabinsk and Chelyabinsk Region. In total, 192 schoolchildren of grades 8-9 were covered by the research. To collect empirical data, the form of survey was used. 


\section{Results and Discussion}

The data obtained showed that adolescents are more likely to use the World Wide Web rather than other sources of information. Books go second judging by the frequency of use. And TV goes third. Newspapers, radio and magazines by the frequency of use took the last three places in the sample under study.

Priority of the Internet as a source of information among young people may be explained by the fact that TV looses to the Internet in such parameters as urgency, interactivity, and the selection of programs to use.

Equally important is the fact that adolescents also considered books as a source of information. The researchers believe that it is education that fosters the habit to read, and to receive information from books, magazines, and other scientifically based sources [31].

The big picture however validates the results of the study that show that, within 10 years, the children and adolescent users of the Internet have increased by five times - from $21 \%$ in 2006 to $100 \%$ in 2016 [33].

The adolescents receive all essential information required in education particularly from the Internet. While reading books has significantly declined.

In our study, to the question "Do you read other books besides textbooks?" $38 \%$ of respondent replied in the affirmative. This is $15 \%$ more than the number of adolescents who replied that they read books in their free time (23\%). Though $49 \%$ seldom read books and $10 \%$ (one in ten) do not read at all. It means that more than a half either do not read books at all or hardly ever do that.

The adolescents mostly find information about books on forums $(27 \%)$, publishing houses websites $(23 \%)$ or on blogs $(19 \%)$.

There are some examples of books that today's adolescents of grades 8-9 read. We collected replies of $23 \%$ of respondents who read books in their free time.

We should mention the main stories specified by the respondents in their questionnaires. These are women's love stories, detectives, adventurous novels by modern writers: "School for fatties" by Natalia Nesterova, books by Ekaterina Vil'mont, "Looking for a Snow Queen" by Oleg Roy, "Metro 2033-2035" by Dmitry Glukhovsky; books by Stephen King: "It", "Carrie", "Under the Dome"; "The Glass Castle" by Jeannette Walls, etc.; and by the writers of the past: "Gone with the Wind" by Margaret Mitchell, "The Count of Monte Cristo" by Alexander Dumas, "Flowers for Algernon" by Daniel Keyes, "A study in Scarlet" by Arthur Conan Doyle, as well as Russian classical literature: "Woe from Wit (Gore ot Uma)" by Alexander Griboedov, "War and Peace" by L.N. Tolstoy, "Dead Souls (Mjórtvyje dúshi)» by Nikolai Gogol; fairytales - "Starik Khottabytch", "Wild Swans". The adolescents also read modern adolescent literature: books of the "Divergent" series by Veronica Roth (writtern in the genre of post-apocalyptic anti-utopia), books about Harry Potter the wizard by J.K. Rowling (fantasy), " 50 days before my suicide" by Stace Kramer.

The abovementioned shows that adolescents prefer literature in the genres of "horror", post-apocalyptic utopia, fantasy, detective stories. These genres correlate with ambivalent complex emotional experience of the adolescents. Together with the heroes of the books the adolescents try different modes of behavior and action, feel their feelings that helps them find self-identity and analyze crisis situations in choosing the ways to solve them (including imagining their own death as a way out of life difficulties). In this way they get rid of the tension accumulated in the course of life being.

Along with the books, adolescents search the Internet for other information. In particular, males and females have different interests. Almost a half of female respondents (46\%) replied that they surf the Internet to read about movies and actors. More than a half of male respondents $(55 \%)$ marked that they are interested in computer games. They consider bloggers as significant people. 
It is important to understand how much time adolescents spend for work on the Internet. The research showed that today's adolescent put the Internet communication on a prior place. Significant part of the respondents (40.3\%) replied that they spend "almost all their free time" or "all their free time even during their classes" surfing the Internet. With this, the number of girls who spend their free time in social networks is larger than the number of boys $(\mathrm{F}=4.556, \mathrm{p} \leq 0.03)$. Almost every third replied that the Internet communication takes 2 or 3 hours a day. Only $7.3 \%$ of adolescents surf the Internet less than an hour a day. It means that over a half of respondents spend all their free time surfing the Internet.

To the question "What has changed in your life under the influence of the Internet?" $69.0 \%$ of girls and $38.8 \%$ of boys said that it is thanks to the Internet communication they met more friends. This means the girls rather than boys make friends and communicate with them in virtual space $(\mathrm{F}=16.02, \mathrm{p} \leq 0.01)$. One in four $(25.2 \%)$ began to express their emotions and $15.4 \%$ became more tolerant. The adolescents also notice negative changes caused by the Internet. $6.8 \%$ of adolescents became more nervous and $3.7 \%$ of them - more aggressive. Every fifth (22.0\%) did not mark any changes.

Our research may be also proved by other studies which put the Internet on the first place as well $[6,7](72 \%)$. Moreover, in our research the adolescents spend less time for reading, watching TV or doing exercises. Moreover, every tenth does not think about their health.

The results of the study allow us drawing a conclusion that in the recent decade children became active media consumers. Culture of consuming media information for them is an important factor of successful socialization. Through mass media they obtain not only information, but ideas, worldview, values, demands, interests, attractions, which are assimilated by them through the mechanisms of identification and imitation. In the present time, mass media form almost $80 \%$ of personal and social opinion. In this regard media safety is considered to be an important condition for developing a healthy personality.

One of the main factors of media safety is "information literacy" which is understood as a skill to "read", analyze and synthesize information, an ability to use computer and media tools, knowledge of informatics and information technologies.

The significant part of the children do not master the skills of critical analysis of the information obtained, neither have they had skills of effective self-control in the sphere of media information consumption. The Internet resources contain various useful or useless information and sometimes even information that destruct them from educational activities.

The level of consuming culture development is much lower than the development of the tools and means of its production and consuming, which accordingly results in a consumers' vulnerability and their dependence on the information space. To increase the quality of informal education we need some programs on developing conscious media consumption in the young generation.

\section{Findings}

Today's adolescents are active participants of media space that allows considering the informal education as an important component of educational environment.

Within the structure of media consumption of adolescents the Internet takes the first place, books go second and TV goes third. With that over a half of adolescents spend most of their free time surfing the Internet. They use the Internet to communicate, entertain, and receive important information. The female adolescents replied they read about films or actors on the Internet. More than a half of male adolescents pointed out that they are mostly interested in computer games. They also consider bloggers as credible.

The Internet has both positive and negative impact on adolescents. According to their own words thank to the Internet they met more friends, began to express their opinion, and 
became more tolerant. However, we can also see the higher level of embarrassment and aggression.

Adolescents prefer literature of such genres as "horror", post-apocalyptic anti-utopia, fantasy, detectives. These genres correlate with ambivalent complex emotional experience of the adolescents. Together with the heroes of the books the adolescents try different modes of behavior and action, feel their feelings that helps them find self-identity and analyze crisis situations in choosing the ways to solve them.

Thus, the media space is a significant institution of socialization for today's adolescents. And in this regard the question of media safety and improving the quality of informal education is considered to be of the highest importance.

\section{References}

1. E. Ya. Varshavskaya, Sociological Research, 9 (2016)

2. A. S. Burelomova, Social psychology (Moscow, 2013)

3. I. I. Vartanova, Psychological Science and Education, 22, 3 (2017)

4. Widlund., H.Tuominen, J. Korhonen, Frontiers in psychology, 9, 297 (2018)

5. L. G. Guslyakova, Social sciences and social education (Moscow, 2004)

6. A. A. Glazkov, International Magazine of Applied and Basic researches, 10, 2 (2015)

7. J. Mao, Computers in Human Behavior, 33 (2014)

8. N. A. Zhuravleva, Psychological Journal, 34, 5 (2013)

9. V. S Sobkin, Pedagogy, 8 (2016)

10. L. Favotto, V Michaelson., C. Davison, International Journal of Qualitative Studies on Health and Well-being, 12, 1 (2017)

11. S. Naeemi, E. Tamam, Child Indicators Research, 10, 4 (2017)

12. A. Chandra, The Brown University Child and Adolescent Behavior Letter, 32, 3 (2016)

13. U. Obersta, V. Renau, A.Chamarro, X. Carbonell, Computers in Human Behavior, 60 (2016)

14. S. D. Young, A. H. Jordan, Cyberpsychology, Behavior, and Social Networking, 16, 4 (2013)

15. L. Korol, S. Maksymets, Science and Education, 5 (2016)

16. M. L. McNicol, E. B. Thorsteinsson, Cyberpsychology, Behavior, and Social Networking, 20, 5 (2017)

17. D. A. Scott, B. Valley, A. B. Simecka, International Journal of Mental Health and Addiction, 15, 3 (2017)

18. S. Lee, M. S. Park, C. Tam, Cyberpsychology: Journal of Psychosocial Research on Cyberspace, 9, 2 (2015)

19. H. Wang, X. Shao, EURASIA Journal of Mathematics, Science and Technology Education, 13, 12 (2017)

20. A. Metzler, H. Scheithauer, Frontiers in Psychology, 8 (2017)

21. S. Areepattamannil, M. S Khine, Computers in Human Behavior, 73 (2017)

22. R. T. Keating, H. M. Hendy, S. H. Can, Computers in Human Behavior, 57 (2016)

23. N. V. Sivrikova, V. F. Zherebkina, M.I. Postnikova, Russian Psychological Journal, 14, 3 (2017) 
24. G. Floros, K. Siomos, Cyberpsychology, Behavior, and Social Networking, 15, 8 (2012)

25. U. Obersta, Computers in Human Behavior, 60 (2016)

26. S. Tifferet, I. Vilnai-Yavetz, Computers in Human Behavior, 35 (2014)

27. V. Barker, CyberPsychology \& Behavio, 12, 2 (2009)

28. D. Williams, Journal of Communication, 59, 4 (2009)

29. E. A. Erofeyeva, Facet Knowledge, 2, 7 (2010)

30. N. S. Kozlova, E. N. Komarova, Theoretical and Applied Aspects of Modern Science, 3, 3 (2014)

31. S. L. Trojanskay, Bulletin of the Chelyabinsk State University, 22, 313 (2013)

32. E. G. Chernikova, N.A. Sokolova, Herald of Chelyabinsk State Pedagogical University, 3 (2015)

33. S. N. Scheglova-Mayorova, Childhood of the XX century in socio-humanitarian prospective: new theories, events and concepts (Moscow, 2017) 